University of Nebraska - Lincoln

DigitalCommons@University of Nebraska - Lincoln

\title{
Pilot study for a sperm quality-based reproductive assessment scheme for deer
}

Lawrence V. Tannenbaum

Army Institute of Public Health, larry.tannenbaum@us.army.mil

Barrett E. Borry

Army Institute of Public Health, barrett.borry@us.army.mil

Follow this and additional works at: https://digitalcommons.unl.edu/usarmyresearch

Tannenbaum, Lawrence V. and Borry, Barrett E., "Pilot study for a sperm quality-based reproductive assessment scheme for deer" (2012). US Army Research. 228.

https://digitalcommons.unl.edu/usarmyresearch/228

This Article is brought to you for free and open access by the U.S. Department of Defense at DigitalCommons@University of Nebraska - Lincoln. It has been accepted for inclusion in US Army Research by an authorized administrator of DigitalCommons@University of Nebraska - Lincoln. 


\title{
Pilot study for a sperm quality-based reproductive assessment scheme for deer ${ }^{\text {is }}$
}

\author{
Lawrence V. Tannenbaum $^{\mathrm{a}, *}$, Barrett E. Borry ${ }^{\mathrm{b}}$ \\ a Army Institute of Public Health, Environmental Health Risk Assessment Program, MCHB-IP-REH, Bldg. 1675, APG-EA, MD 21010-5403, USA \\ ${ }^{\mathrm{b}}$ Army Institute of Public Health, Groundwater and Solid Waste Program, MCHB-TS-EGW, Bldg. 1677, APG-EA, MD 21010-5403, USA
}

\section{A R T I C L E I N F O}

\section{Article history:}

Received 26 January 2011

Received in revised form 18 May 2011

Accepted 23 May 2011

\section{Keywords:}

Sperm

Sperm count

White-tailed deer

Ecological risk assessment

Reproduction

\begin{abstract}
A B S T R A C T
Ecological risk assessments (ERAs) for mammals at chemically contaminated terrestrial sites conventionally apply a food-chain model to draw inferences about a population's reproductive condition. Very recently though, the ERA field was advanced beyond the desktop level with the introduction of Rodent Sperm Analysis (RSA), a direct health status assessment method for the actual chemically exposed site receptor. Here, the sperm parameters of rodents (count, motility, morphology) of contaminated sites and their habitat-matched noncontaminated reference locations are comparatively reviewed for a technically supported indication of reproductive capability, ERA's toxicological endpoint of greatest concern. With the extent to which sperm parameters need to be impaired in order to compromise reproduction being known, more definitive determinations are possible than with the food-chain model approach. We sought to adapt the RSA method to the white-tailed deer (Odocoileus virginianus), recognizing that this commonly evaluated mammalian species of ERAs is one of a very few species that avails itself to regularly being removed (through hunting) from the field. We conclude that the adaptation is viable, although sperm motility and a few other measures routinely compiled in RSA applications cannot be collected. In the pilot application, the deer population we assessed, with exposures to Superfund and other sites of known contamination, was not found to have compromised reproduction. This finding is consistent with RSA's supporting theory as well as population census information. The outcomes of socalled deer sperm analysis applications for herds exposed to one or more environmental stressors, have the potential to serve as reliable indicators of reproductive status. Such outcomes also provide further weight-of-evidence that suspected contamination is not associated with adverse ecological effects.
\end{abstract}

Published by Elsevier Ltd.

\section{Introduction}

For many mammalian species including humans, the sperm parameters of count, motility, and morphology are recognized to be indicators, if not proven barometers of reproductive capability (Bucci and Meistrich, 1987; Chapin et al., 1997; Gray et al., 1992; Meistrich et al., 1994). For each parameter, it is understood that too great a shift in the direction of nonfavorability (i.e., a lessening of count or motility; an increase in the percentage of abnormally shaped cells) can account for lesser reproduction in such forms as fewer successful matings or smaller-sized litters (Chapin et al., 1997). Seemingly the laboratory rodent model has been the appropriate one to apply in gaining an understanding of the degree to which each parameter must be impaired in

\footnotetext{
The opinions or assertions contained herein are the views of the author and are not to be construed as official or as reflecting the views of the Department of the Army or the Department of Defense.

* Corresponding author. Tel.: +1 410436 5210; fax: +1 4104368170.

E-mail addresses: larry.tannenbaum@us.army.mil (L.V. Tannenbaum), barrett.borry@us.army.mil (B.E. Borry).
}

order to compromise reproduction. Rodents facilitate reproductive biology research because of their relatively small size and easily met housing requirements, achieving sexual maturity in as little as 6 weeks, having a gestation period of less than 1 month, and bearing sizeable litters. In 2003, definitive rodent-derived sperm parameter-based thresholds-for-effect were harnessed to craft Rodent Sperm Analysis (RSA), a reproductive assessment scheme for mammals at contaminated Superfund-type sites (Tannenbaum et al., 2003, 2007). In 2009, RSA, constituting the only direct health status assessment tool for ecological receptors at contaminated sites, and intended to add a field-verification element to the ecological risk assessment (ERA) process, was patented (U.S. Patent No. $7,627,434$, Method for field-based ecological risk assessment using rodent sperm-analysis).

Where rodent populations inhabiting contaminated terrestrial sites bear no evidence of compromised sperm parameters (e.g., reduced count), as can be demonstrated with RSA's comparative assessment scheme, such information is used to conclude that the reproductive health of all other site mammals (e.g., Sylvilagus floridanus, Vulpes vulpes, Neovison vison, Odocoileus virginianus) is also sufficiently protected. Extrapolation from rodents to the larger and wider-ranging mammalian species that may be contacting the 
contaminated sites, and for whose protection soil remedial actions could realistically proceed follows from RSA theory. If rodents, assumed maximally exposed terrestrial receptors (owing to their having constant contact with soil and having highly limited home ranges that effectively bind them to contaminated sites), bear no signs of reproductive impairment, the same should be true for other site mammals that have a far lesser degree of contact with affected soils (Tannenbaum et al., 2003, 2007). The extrapolation scheme is also consistent with conventional ERA practice, where with almost no exception, laboratory rodent-derived chemical dose-response data are used in the desktop assessments for all other mammals (Kolluru, 1996; U.S. EPA, 1997; Sample et al., 1996).

Although RSA outcomes can be and have been used to assess the reproductive health of white-tailed deer (O. virginianus; SAIC, 2001), in theory this species should in itself be able to submit to a direct reproductive health status assessment scheme that is nearly isomorphic to RSA. With RSA, the strategic placement of baited live animal traps at both a Superfund/hazardous waste site and its habitat-matched, noncontaminated reference location, furnishes the requisite numbers of small rodents to be analyzed. Seemingly, requisite numbers of reproductive tissue specimens to allow for a valid comparison in deer can be secured via coordinated hunting programs. The subject study describes a fall 2009 pilot effort with two specific aims. First explored is the practicability of adapting the RSA method such that sperm quality in deer can serve as an indicator of that species' reproductive capability. Second, the reproductive capability of a white-tailed deer population with exposure to sites with industrial and other contamination inputs (and potentially bearing chemical residues, principally metals and explosives) is assessed.

\section{Materials and methods}

\subsection{Study areas}

The Aberdeen Area of Aberdeen Proving Ground (APG-AA), the U.S. Army's oldest active proving ground located in southern Harford County, Maryland, and a Superfund site, (Fig. 1), constituted the contaminated site. APG-AA encompasses approximately 25,000 acres, and contains a number of operational ranges. Activities include various research and development testing, firing ranges, and open burn/open detonation of munitions components. Much of the peninsula is utilized for the testing of large and medium caliber munitions as well as some small caliber training and specialized equipment testing. Eastern Neck Wildlife Refuge (ENWR), situated approximately $45 \mathrm{~km}$ to the southwest of APG-AA in Rock Hall, Kent County, Maryland (Fig. 1) was selected as the study's noncontaminated reference location. In addition to ENWR fringing the Chesapeake Bay as does APG-AA, and the habitats of the two locations being similar (qualitatively) in terms of terrain and vegetation, their muzzleloader hunts perfectly coincided (discussed further in Section 4.1). En route to assembling the data to support the development of an RSA-parallel method for deer, the intent of the study was to harvest the scrotums of 10 bucks from each location. A sample size of 10 conforms both to the desired (minimum) number of adult male rodents to be collected from the trapping sites of RSA applications (Tannenbaum et al., 2003) and to the recommended number of animals of either sex in reproduction/developmental toxicity screening tests (USEPA, 2000).

\subsection{Hunter participation}

Hunters arriving at the APG-AA deer check-in station each day for the muzzleloader hunt were asked to comply with a deer reproduction study. Participating hunters were given a small ice cooler containing two frozen ice packs, a plastic ziplock bag, and a marking pen. An instruction sheet directed the hunters to remove the entire scrotum from a buck when field-dressing their kill, to place the scrotum in the bag, to record on the bag the date and time of kill and the buck's antler point number, and to place the bag between the ice packs inside the cooler (with the aid of rubber bands and foam stuffing). Hunters returning to the check-in station from the field were further instructed to give their samples to on-duty personnel who would transfer them to a $-20^{\circ} \mathrm{C}$ freezer located there. On-duty personnel recorded the field-dressed weights of the bucks and kept these records with each animal's uniquely assigned number that was also on the ziplock bag. Within a day or two of arrival at the check-in station, all the scrotum samples were transferred to a $-80^{\circ} \mathrm{C}$ freezer located at APG-Edgewood Area (APG-EA) and were kept in the deep freezer until analyzed.

Participants at ENWR's 1-day hunt were asked to call the refuge office on their cell phones as soon as they knew that they had taken a buck. A study coordinator then drove to the vicinity of the kill, usually arriving shortly after the time the hunter had located it. The scrotums were removed and kept on ice in the single large, icepacked cooler that was driven to the different stands that called in with kill information that day. The scrotums were taken to APG-EA at the end of the day, placed in a $-20^{\circ} \mathrm{C}$ freezer, and transferred a few days later to the previously mentioned $-80^{\circ} \mathrm{C}$ freezer. The field-dressed weights for these bucks, linked to hunter-unique identification numbers and recorded by on-duty personnel at the ENWR check-in location, were provided to the study coordinator at the end of the 1-day hunt.

\subsection{Sample analysis}

Samples were processed several weeks later by Charles River Laboratories, Pathology Associates (Frederick, MD). The procedures for evaluating sperm counts and sperm morphology paralleled those used for rodents as described in Tannenbaum et al. (2007). Briefly, after each sample was completely thawed, the scrotal sac was cut, one testis was removed, and its epididymis was trimmed away. The caudal section of the epididymis was first weighed to four decimal places and homogenized in 40 milliliters ( $\mathrm{mL}$ ) of deionized water for 2 min using a Waring commercial blender (Model 51BL32), after which the suspension was transferred to a plastic test tube. After vortexing briefly, the sperm heads were stained (to assist with the automated counting of sperm) by pipetting a 100 microliters $(\mu \mathrm{L})$ sample of the homogenate into a violet reaction vial containing a Hoechst dye (H33342) pellet that had first been dissolved with the addition of $100 \mu \mathrm{L}$ of deionized water. A $9 \mu \mathrm{L}$ sample of the stained sperm was then placed onto a 20 -micron $(\mu \mathrm{m})$ deep Cell-Vu glass slide which was loaded into a Hamilton Thorne Integrated Visual Optical System (IVOS) sperm analyzer programmed to read 20 fields along the slide. The recorded counts were adjusted for caudal epididymal weight (i.e., so that the count could be expressed as millions of sperm/gram (g) of cauda epididymis), as is routinely done in rodent work overall, and has been the standard practice for RSA applications.

For the sperm morphology measure, two eosin-stained slides were prepared for each animal following the procedure described in Tannenbaum et al. (2007). A minimum of 200 sperm cells per animal were examined for as many as four different abnormalities in both the head and the tail.

\subsection{Statistical analysis}

Standard $t$-tests were applied to support multiple-feature comparisons for the two deer populations. Specifically, population body weights, sperm counts, morphologically abnormal (sperm) cell 


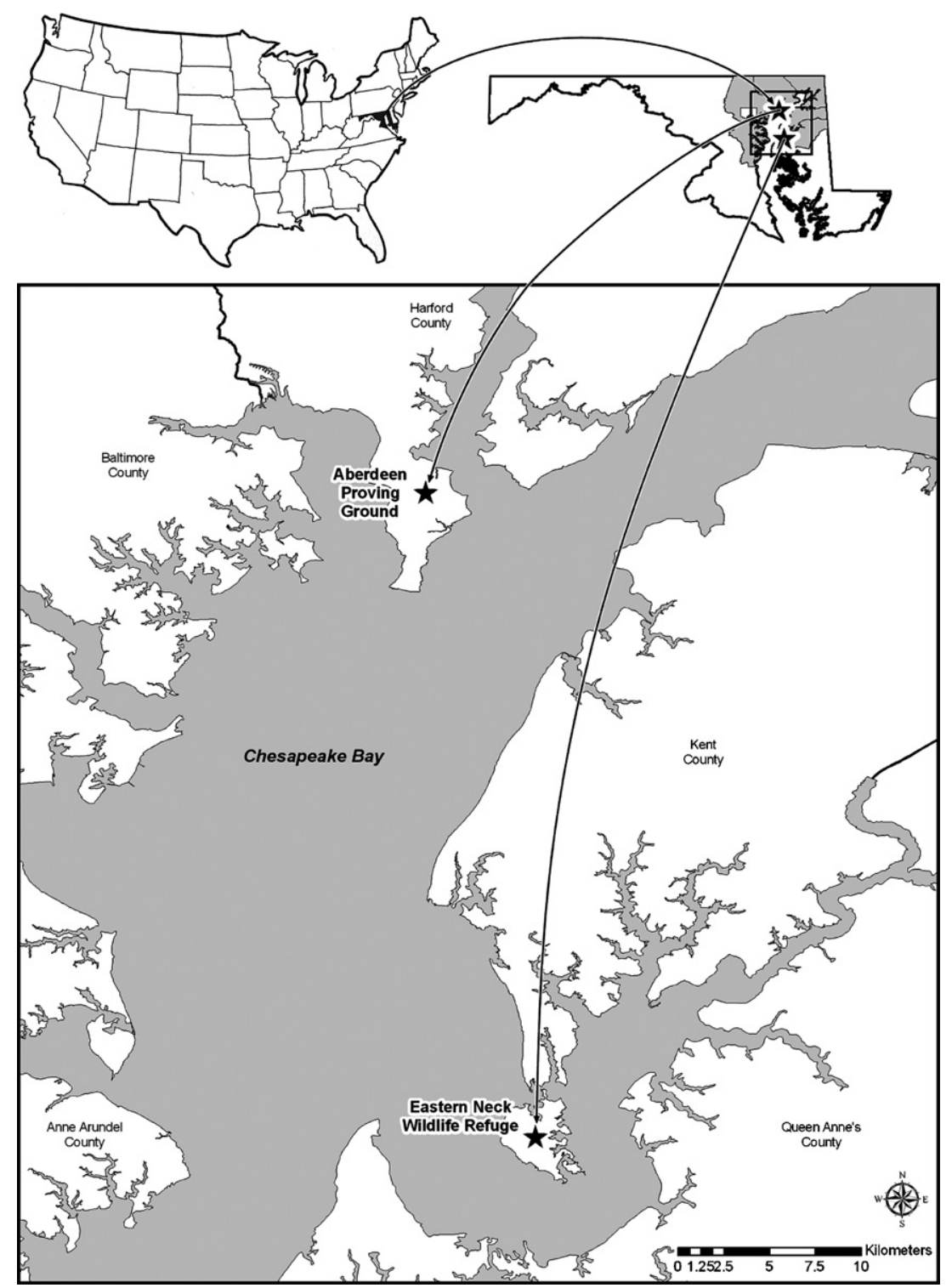

Fig. 1. Locations of the two Maryland deer populations of the pilot deer sperm analysis method application.

frequencies, and organ-to-body weight ratios for the testes and the epididymis were statistically evaluated this way.

\section{Results}

\subsection{Hunt success}

Thirty-seven deer were taken in the week-long muzzleloader hunt at APG-AA. Of the 18 that were males, 14 had scrotums returned to the deer shack by participating hunters. Of these, four were antlerless button bucks with field-dressed weights of approximately 40 pounds. Due to their immaturity, they were not suitable for the subject sperm quality-based reproductive assessment pilot. The 10 APG-AA bucks were harvested on 3 different days of the weeklong hunt; 3 on 18 October, 1 on 19 October, and 6 on 23 October. The 10 ENWR bucks utilized in the subject study were the first bucks taken (of an overall 33 animals) on the single hunt day (October 19). All 10 of these bucks were taken between 08:00 and 10:30 h. Although dentition and other assessment approaches were not employed in aging the bucks (Hamlin et al., 2000), our best professional judgment when considering the body weights and the antler sizes is that all of the bucks were sexually mature and greater than 1-1/2 years old. In accounting for the greater ENWR population's body weight (although not statistically greater), the weights of the three heaviest ENWR bucks were higher than that of the overall heaviest APG-AA buck (Table 1).

\subsection{Hunter compliance}

Hunters at both locations exhibited a great willingness to support the pilot DSA study. At APG-AA, all the ice coolers and associated equipment (approximately 15 sets) were readily taken by hunters to the field each morning of the hunt, and all coolers were returned at the end of each day. There were two hunters who did not perfectly follow the instructions provided, having skinned away the scrotal sac from the samples (testes) they returned. This did not affect the quality of the sample, as there was ample muscle and other tissues protecting the epididymides. None of the ENWR hunters expressed any reservations with regard to scrotums being removed before they commenced field dressing their take. In most cases they allowed the study representative to remove the scrotum. 
Table 1

Field-dressed body weights ${ }^{\mathrm{a}}$ and antler point information of the deer sperm study.

\begin{tabular}{|c|c|c|c|}
\hline \multicolumn{2}{|c|}{ Eastern neck wildlife refuge } & \multicolumn{2}{|c|}{$\begin{array}{l}\text { Aberdeen proving ground, } \\
\text { Aberdeen area }\end{array}$} \\
\hline Weight (pounds) & Points & Weight (pounds) & Points \\
\hline 85 & 1 & 82 & 5 \\
\hline 85 & 5 & 84 & 5 \\
\hline 115 & 2 & 84 & 8 \\
\hline 115 & 4 & 96 & 6 \\
\hline 115 & 4 & 113 & 6 \\
\hline 120 & 2 & 113 & 8 \\
\hline 125 & 4 & 114 & 6 \\
\hline 135 & 6 & 116 & 6 \\
\hline 136 & 8 & 118 & 10 \\
\hline 145 & 8 & 125 & 10 \\
\hline Mean: 117.6 & & Mean: 104.5 & \\
\hline S.D.: 20.00 & & S.D.: 16.29 & \\
\hline
\end{tabular}

a Arranged from lightest to heaviest.

\subsection{Sperm measures}

As Table 2 illustrates, the variation in sperm counts for the two populations was quite similar. Each population had the bulk of its measures in the range of approximately 1100 to almost $2000 \times 10^{6} \mathrm{sperm} / \mathrm{g}$ of cauda epididymis, and each population included one animal with a particularly low count (i.e., an order of magnitude less than all of the others). Mean population sperm count was not statistically different for the APG-AA and ENWR deer, although the APG-AA population had an arithmetically higher count. Similarly, the percentage of misshapen (sperm) cells was not statistically different for the two deer populations sampled. The computed organ-to-body weight ratios for the two populations were nearly identical, and again not statistically different.

\section{Discussion}

\subsection{Deer sperm analysis (DSA) method feasibility}

Based on the pilot DSA study, planning and implementing DSA is a workable, albeit more involved enterprise than is RSA. DSA requires decidedly greater efforts in securing a proper, noncontaminated reference location and in determining when to collect data, than does its established RSA counterpart. An additional DSA element not found with RSA, is the former's dependency on hunter assistance and coordination.

Reference location selection in support of DSA necessarily incorporates considerations of the spatial movements of deer. Due to white-tailed deer having home ranges in the hundreds of acres, contaminated ranging lands and relatively pristine ranging lands must necessarily be substantially distanced from one another (perhaps by tens of miles) in order to preclude the possibility that animals contact both. The further away from the contaminated ranging lands of interest one travels in locating a potentially suitable reference area, the greater the possibility that site topography, soil type, vegetative cover, and other habitat features will differ for the two ranging areas. Such differences could interfere with the essential sperm parameters evaluation that forms the essence of DSA. This arrangement contrasts with that of RSA, where the very limited spatial movements of field rodents (e.g., white-footed mouse, meadow vole) allow for valid reference locations to be no more than perhaps $0.8 \mathrm{~km}$ from their paired contaminated sites. As a consequence of trapping sites being so near one another, the RSA requirement of having at least one commonly occurring species is easily met. Additionally, because habitat features for the two trapping sites will likely highly align, reasonably it is only the chemical-in-soil presence at the contaminated parcel that distinguishes the two. Should sperm parameter-based thresholds-for-effect be exceeded in contaminated site rodents, causation can generally be assigned to the chemical-in-soil influences (Tannenbaum et al., 2003, 2007). Potentially with DSA though, in the event that contaminated site deer have one or more sperm parameter thresholds-for-effect exceeded, there may be greater uncertainty in concluding that soil chemistry was the cause.

Considerations of the reproductive behavior of deer make for the indispensible DSA requirement that tissue collection from both sites necessarily occur on nearly the very same dates. This follows from sperm counts in deer varying substantially within a period of only a few weeks within a season (e.g., pre-rut, postrut; Lambiase et al., 1972). This situation is also in stark contrast to that of field rodents, highly promiscuous species that mate multiple times each night, and where the repeated copulatory behavior of adult males is assumed to equitably lower sperm counts in a population (Dewsbury and Sawrey, 1984). In securing a viable reference location from the vantage point of the deer's reproductive cycle, our approach was to review the dates of APG-AA's various 2009 fall and winter hunts (e.g., bow, muzzleloader, firearms), and to search for other co-occurring managed hunts in the region (regardless of their take method), with a special emphasis placed on east-central Maryland.

\subsection{Reference location used}

There is good reason to believe that ENWR served as an appropriate reference location from both habitat and reproductive biology considerations. ENWR fringes the Chesapeake Bay as does APG-AA. With ENWR being located only some $48 \mathrm{~km}$ from APG-AA (the linear cross-bay distance), its browse material appeared to be similar to that of APG-AA, although such was not quantified. Habitat differences for APG-AA and ENWR though, must be acknowledged; ENWR has a mixture of intensive agriculture (crops such as corn and soy beans) along with woodlands, whereas APG-AA has a mixture of grasslands and woodlands, with no onpost agriculture. ENWR also well satisfied the reproductive timing requirement; its 1-day managed (muzzleloader) hunt on 19 October fell on the second day of APG-AA's 7-day long hunt that occurred on 18, 19, and 21-25 October.

\subsection{Sperm parameter assessment}

The finding of no difference in sperm counts between the APG-AA and ENWR deer is not surprising, and is consistent with the theory that supports RSA (Tannenbaum et al., 2003, 2007; Tannenbaum, 2005). Sites that submit to ERAs have been contaminated for decades. Short of mammal populations being extirpated from a given locale or landscape due to their contaminant exposures (essentially an unknown phenomenon within a Superfund site context; Tannenbaum, 2003), the excessive time lapse involving tens of generations, has more than likely granted biota in the wild ample opportunity to have adapted to any toxicological stressors that may be present. It is also true that certain organic contaminants in soil, such as the explosives residues from years of installation operations substantially degrade over time, thereby posing lesser health challenges. The absence in APG-AA deer of a shift in sperm count, the sperm parameter that is most easily compromised in response to chemical stressors, reflects two other noteworthy realities. First, effect-level concentrations of metals and explosives may have never been amassed in APG-AA soils, even with the installation's munitions testing mission continuing to the present day. Second, it is unlikely that a sufficiently large parcel of land at APG-AA and its contiguous offpost area would become substantially contaminated to the point that a wideranging species such as white-tailed deer could be disaffected. The 
Table 2

Comparative assessment of reproductive features.

\begin{tabular}{|c|c|c|c|c|}
\hline \multirow[t]{2}{*}{ Location } & \multirow[t]{2}{*}{ Sperm count $\left(10^{6} \mathrm{sperm} / \mathrm{g}\right)$} & \multirow{2}{*}{$\begin{array}{l}\text { Abnormal cells }{ }^{\mathrm{a}} \\
\text { (per count of } 200 \text { ) }\end{array}$} & \multicolumn{2}{|c|}{ Organ-to-body weight ratios } \\
\hline & & & Testes & Epididymis \\
\hline \multirow[t]{12}{*}{ ENWR } & 696.6 & 3 & 0.0018 & 0.00019 \\
\hline & 1362.1 & 0 & 0.0024 & 0.00015 \\
\hline & 1825.4 & 2 & 0.0017 & 0.00015 \\
\hline & 1600.7 & 2 & 0.0022 & 0.00015 \\
\hline & 1793.3 & 0 & 0.0018 & 0.00012 \\
\hline & 1421.1 & 2 & 0.0026 & 0.00016 \\
\hline & 781.1 & 19 & 0.0017 & 0.00012 \\
\hline & 1733.8 & 0 & 0.0022 & 0.00009 \\
\hline & 1007.5 & 0 & 0.0018 & 0.00014 \\
\hline & 116.1 & 6 & 0.0020 & 0.00014 \\
\hline & Mean: 1233.8 & Total: 34 & Mean: 0.002 & Mean: 0.00014 \\
\hline & S.D.: 567.0 & \% Abnormal: 1.7 & S.D.: 0.0003 & S.D.: 0.00003 \\
\hline \multirow[t]{12}{*}{ APG-AA } & 1903.5 & 2 & 0.0019 & 0.00016 \\
\hline & 2058.0 & 4 & 0.0020 & 0.00018 \\
\hline & 1663.0 & 5 & 0.0025 & 0.00024 \\
\hline & 34.3 & 22 & 0.0012 & 0.00015 \\
\hline & 2372.4 & 2 & 0.0017 & 0.00014 \\
\hline & 1574.9 & 0 & 0.0020 & 0.00012 \\
\hline & 1140.0 & 5 & 0.0018 & 0.00018 \\
\hline & 1136.3 & 2 & 0.0022 & 0.00027 \\
\hline & 1076.2 & 0 & 0.0015 & 0.00018 \\
\hline & 1075.8 & 3 & 0.0020 & 0.00015 \\
\hline & Mean: 1403.4 & Total: 45 & Mean 0.0019 & Mean: 0.00018 \\
\hline & S.D.: 662.0 & \% Abnormal: 2.3 & S.D. 0.0004 & S.D.: 0.00005 \\
\hline
\end{tabular}

a Includes head categories of: amorphous, small, enlarged, or double; and tail categories of coiled, bent, double, or 'other'.

detonations occur at fixed locations and are unlikely to leave a contamination footprint that is spatially relevant to the movements of deer. Importantly, to the extent that the established sperm count threshold-for-effect (of a $60 \%$ reduction relative to the reference population) has not been exceeded, the data suggest that deer with exposure to contaminated APG-AA soils are not reproductively compromised. This is consistent with the absence of reports of a dwindling installation herd over the many years that it has been monitored and censused. It is also consistent with deer studies conducted at APG and other Army installations documenting that explosives (and their breakdown products), polychlorinated biphenyls, and organochlorine pesticides do not accumulate in the muscle and liver, and that metals accumulations in these tissues are no different from those of background (USAEHA, 1994; USACHPPM, 1995).

For the one animal of each population that had a distinctive and comparatively low sperm count, we would plausibly suggest that this reflects these particular animals having mated earlier than the others, and having done so only shortly before being taken in the hunt. Lambiase et al. (1972) discuss a pronounced depletion of sperm reserves in white-tailed deer that mate several times daily for more than a few successive days. The correlation of lowered count (also termed sperm output) in mammals relative to the time of mating and to mating frequency is discussed in the literature (Hale and Almquist, 1960), and particularly for rodents that avail themselves so well to study (Dewsbury and Sawrey, 1984).

Our means of expressing sperm count is unique and deserving of attention. First, we are not aware of any routine approach to sperm sample collection in free-roaming deer, or that any standardized means of expressing count exists for such animals. It appears that heretofore, count in this species has only been characterized for the purpose of providing empirical reproductive biology information, as in developing an understanding of how count varies with age or by season (Lambiase et al., 1972; Nelson and Johnson, 1990). Count information in deer has not previously been gathered for use in ERA's although (a) reproduction is the toxicological endpoint of greatest concern in ERA, (b) sperm count in mammals is not only an indicator, but an established barometer of reproductive success, and (c) white-tailed deer is a commonly assessed species representing the large herbivorous mammal guild in ERAs. We further find standardization lacking where tissue homogenates have been used to assess count. The inconsistency begins with the choice of tissue to employ (paired testes, capit epididymis, or cauda epididymis) and extends to the expression of count as either relative to the homogenate volume or the tissue weight. We adapted the highly standardized method used with rodents of selecting the cauda epididymis (where sperm are stored) to work with, and expressing the count relative to its weight. Although we employed a sophisticated IVOS for the counting, a hemacytomer and light microscope could have been used in lieu of this.

Sperm morphology in mammals is a highly buffered system, as has been demonstrated repeatedly in studies exposing laboratory rodents to numerous chemicals. It is also reputedly the most sensitive sperm parameter, in that relative to count and motility, it requires a substantially lesser degree of shift (i.e., increase in the percentage of misshapen cells) for fertility to be impacted. Chapin et al. (1997) report that an increase of just $4 \%$ relative to the control condition can cause lesser production of young (as fewer litters or smaller sized litters). Our finding that sperm morphology for the two populations was not statistically different provides another indication that these deer are not reproductively compromised. It is interesting to note that the greatest magnitude shifts in sperm morphology that we have observed in site-exposed rodents, none of which have been statistically significant) have, like the APG-AA deer, been only $\pm 0.6 \%$ relative to reference locations. We also note that the pattern of the occurrence of abnormal cells for the two deer populations (Table 2 ) is strikingly similar. Each population had one animal that curiously contributed approximately $50 \%$ of its total number of misshapen cells (for the 2000 cells counted overall). Additionally and aside from these singular 'higher' values, the remaining values of misshapen cells ranged from 0 to 6 at ENWR and 0 to 5 at APG-AA.

The DSA pilot study had to exclude an analysis of sperm motility, given that such necessitates sperm sample preparations being 
readied for IVOS processing within minutes of animal death, and it being infeasible to deploy an IVOS apparatus to specific deer kill locations this rapidly. To our knowledge, sperm motility has only been measured in normally or electro-ejaculated deer samples, and almost always with penned deer (Lambiase et al., 1972). (This practice, although not workable for DSA, bears the distinct advantage of facilitating the collection of multiple sperm motility measures over time from the same animal.) Our experience with numerous rodent species from diverse locations and habitats is that sperm motility is not the most critical of the three sperm parameters to monitor (Tannenbaum et al., 2007, 2008). In fact, in nearly all RSA applications to date, we observed the sperm motility to be higher at the contaminated sites (although never statistically so), and it has further been reasoned that such might reflect a compensatory mechanism at play (Tannenbaum et al., 2007). Where sperm counts are reduced in contaminated site rodents, as is often the case, it could only be beneficial for these animals to have a greater percentage of sperm that are moving normally. Importantly, we conclude that despite the inability to assess sperm motility, there remains great utility in adapting the RSA method as we have done here, to be able to assess chemically exposed deer populations.

\section{Conclusions}

Based on the foregoing, it appears that the DSA method constitutes a viable and low cost means of assessing the reproductive capability of deer populations exposed to one or more environmental stressors. The method is desirable because of its nondestructive nature; deer taken through managed hunts can supply the tissues needed for the assessment, and the efforts to collect the samples need not interfere with hunter activities. Unavoidably the DSA method, in a number of ways, departs from RSA after which it is patterned. Sperm motility analysis, one of three standard sperm parameter evaluations in rodents and other species including man, is technically infeasible. Standard organ-to-body weight ratios (e.g., for the liver, kidneys, etc.) that can supply corroborative information are not possible because the deer's internal organs are removed in the field prior to animals being brought to check-in areas and weighing stations. Testes/body weight ratios and epididymis/body weight ratios are meaningless to compute due to scaling factors. Despite these data gaps, DSA holds certain advantages over RSA. With managed hunt scenarios, it is possible to collect 10 or 15 suitable bucks from both a contaminated site and a reference location over a much narrower time window than can equivalent numbers of small rodents. Consequently, animal trapping field labor costs are less than those of RSA. Costs are further reduced because samples can be shipped off to a laboratory for analysis, whereas RSA requires critical analyses (i.e., sperm motility) to be conducted in an onsite mobile laboratory shortly after animal capture, over as many days as rodents are collected.

In implementing DSA, the bulk of the effort is front-loaded in the sense that considerable care must go into locating a suitable reference location. Aside from having comparable habitat and nearly identical take dates as that of the site of interest, coordination with management personnel and hunters must occur. In contrast with RSA, the greater share of the effort is expended in the field. The number of trap nights is often uncertain, animal capture success is highly subject to recent weather events, and intended reference locations may be found to not yield the same species as that collected at the site of interest.

Regarding our effort to assess the APG-AA deer population, our work discovers that the cauda epididymis is amenable to homogenization and subsequent sample preparation as a parallel procedure to that of RSA. The sperm count and sperm morphology measures appear to serve as viable indicators of reproductive capability as they do for the patented RSA process. Importantly, DSA applications hold the potential to provide further weight-of-evidence that adverse ecological effects are not associated with receptor exposure to contaminated environmental media.

\section{Acknowledgements}

The authors wish to first thank the U.S. Army Environmental Command (Mr.Jim Daniel) for funding this study. We also thank Mr. Tom Ward of the Aberdeen Archery Club, the employees and volunteer hunters of APG-AA's deer check-in station, and the U.S. Fish and Wildlife Service personnel that managed the ENWR's hunting program. The helpful comments on the manuscript of Mr. Dennis Druck and Ms. Sherri Hutchens are appreciated as are the editing skills of Ms. Joyce Woods.

\section{References}

Bucci, L.R., Meistrich, M.L., 1987. Effects of busulfan on murine spertmatogenesis: cytotoxicity, sterility, sperm abnormalities, and dominant lethal mutations. Mutat. Res. 176, 259-268.

Chapin, R.E., Sloane, R.A., Haseman, Haseman, J.K., 1997. The relationships among reproductive endpoints in Swiss mice, using the reproductive assessment by continuous breeding database. Fundam. Appl. Toxicol. 38, 129-142.

Dewsbury, D.A., Sawrey, D.K., 1984. Male capacity as related to sperm production, pregnancy initiation, and sperm competition in deer mice (Peromyscus maniculatus). Behav. Ecol. Sociobiol. 16, 37-47.

Gray, L.E., Marshall, J.O., Setzer, R., 1992. Correlation of ejaculated sperm numbers with fertility in the rat. Toxicology $12,433$.

Hale, E.B., Almquist, J.O., 1960. Relation of sexual behavior to germ cell output in farm animals. J. Dairy Sci. 43, 145-167.

Hamlin, K.L., Pac, D.F., Sime, C.A., DeSimone, R.M., Dusek, G.L., 2000. Evaluating the accuracy of ages obtained by two methods for Montana ungulates. J. Wildl. Manage. 64, 441-449.

Kolluru, R.V., 1996. Health assessment: principles and practices. In: Kolluru, R.V., Bartell, S., Pitblado, R. (Eds.), Risk assessment and management handbook., pp. 4.3-4.68.

Lambiase, J.T., Amann, R.P., Lindzey, J.S., 1972. Aspects of reproductive physiology of male white-tailed deer. Reprod. Physiol. Deer 36, 868-875.

Meistrich, M.L., Kasai, K., Olds-Clarke, P., MacGregor, G.R., Berkowitz, A.D., Tung, K.S.K., 1994. Deficiency in fertilization by morphologically abnormal sperm produced by azh mutant mice. Mol. Reprod. Develop. 37, 69-77.

Nelson, T.A., Johnson, M.W., 1990. Fecundity of male white-tailed deer on Holla Bend National Wildlife Refuge. Proc. Arkansas Acad. Sci. 44, 83-85.

Sample, B.E., Opresko, D.M., Suter, G.W., 1996. Toxicological Benchmarks for Wildlife: 1996 Revision, ES/ER/TM-86/R3. Oak Ridge National Laboratory, Oak Ridge, TN.

Science Applications International Corporation. 2001. Phase II Remedial Investigation Report for the Winklepeck Burning Grounds at the Ravenna Army Ammunition Plant, Ravenna, Ohio, Volume 1 - Main Text. Oak Ridge, TN.

Tannenbaum, L.V., 2003. Can ecological receptors really be at risk? Hum. Ecol. Risk Assess. 9, 5-13.

Tannenbaum, L.V., Bazar, M., Hawkins, M., Cornaby, B.W., Ferguson, E.A., Carroll, L.C., Ryan, P.F., 2003. Rodent sperm analysis in field-based ecological risk assessment: pilot study at Ravenna Army Ammunition Plant, Ravenna, Ohio. Environ. Pollut. 123, 21-29.

Tannenbaum, L.V., 2005. A critical assessment of the ecological risk assessment process: a review of misapplied concepts. Integr. Environ. Assess. Manage. 1, 66-72.

Tannenbaum, L.V., Thran, B.H., Williams, K.J., 2007. Demonstrating ecological receptor health at contaminated sites with wild rodent sperm parameters. Arch. Environ. Contam. Toxicol. 50, 459-465.

Tannenbaum, L.V., Thran, B.H., Williams, K.J., 2008. Testing the limits of rodent aperm analysis: Azoospermia in an otherwise healthy wild rodent population. Arch. Environ. Contam. Toxicol. 56, 157-164.

U.S. Army Environmental Hygiene Agency, 1994. Final Report Project No. 75-51YF23 Health Risk Assessment for Consumption of Deer Muscle and Liver from Joliet Army Ammunition Plant, Joliet Army Ammunition Plant, Joliet, Illinois.

U.S. Army Center for Health Promotion and Preventive Medicine, 1995. Final Field Study No. 7523-YS50-94, Health Risk Assessment of Consuming Deer from Aberdeen Proving Ground, Maryland.

U.S. Environmental Protection Agency, 1997. Ecological Risk Assessment Guidance for Superfund: Process for Designing and Conducting Ecological Risk Assessment. EPA 540-R-97-006, Washington, DC.

U.S. Environmental Protection Agency, 2000. Health Effects Test Guidelines, OPPTS 870.3550, Reproduction/Developmental Screening Test. EPA 712-C-00-367, Washington, DC. 